\title{
Quantitative Analysis of the Principal-Agent Problem in Commercial Buildings in the U.S.: Focus on Central Space Heating and Cooling
}

\author{
Helcio Blum and Jayant Sathaye \\ International Energy Studies Group \\ Lawrence Berkeley National Laboratory \\ Berkeley, CA
}

\begin{abstract}
We investigate the existence of the principal-agent (PA) problem in non-government, non-mall commercial buildings in the U.S. in 2003. The analysis concentrates on space heating and cooling energy consumed by centrally installed equipment in order to verify whether a market failure caused by the PA problem might have prevented the installation of energy-efficient devices in non-owner-occupied buildings (efficiency problem) and/or the efficient operation of space-conditioning equipment in these buildings (usage problem). Commercial Buildings Energy Consumption Survey (CBECS) 2003 data for single-owner, single-tenant and multi-tenant occupied buildings were used for conducting this evaluation. These are the building subsets with the appropriate conditions for assessing both the efficiency and the usage problems. Together, these three building types represent 51.9\% of the total floor space of all buildings with space heating and 59.4\% of the total end-use energy consumption of such buildings; similarly, for space cooling, they represent 52.7\% of floor space and $51.6 \%$ of energy consumption.

Our statistical analysis shows that there is a usage PA problem. In space heating it applies only to buildings with a small floor area ( $\leq 50,000 \mathrm{sq}$. ft.). We estimate that in 2003 it accounts for additional site energy consumption of $12.3\left( \pm 10.5^{1}\right)$ TBtu (primary energy consumption of 14.6 [ \pm 12.4$]$ TBtu), corresponding to $24.0 \%$ ( $\pm 20.5 \%)$ of space heating and $10.2 \%$ ( $\pm 8.7 \%$ ) of total site energy consumed in those buildings.

In space cooling, however, the analysis shows that the PA market failure affects the complete set of studied buildings. We estimate that it accounts for a higher site energy consumption of 8.3 ( \pm 4.0$)$ TBtu (primary energy consumption of 25.5 [ \pm 12.2$]$ TBtu), which corresponds to $26.5 \%$ ( $\pm 12.7 \%)$ of space cooling and $2.7 \%( \pm 1.3 \%)$ of total site energy consumed in those buildings.
\end{abstract}

Keywords: Energy efficiency, commercial buildings, principal-agent, market failures

\footnotetext{
${ }^{1}$ At $95 \%$ confidence interval.
} 


\section{Contents}

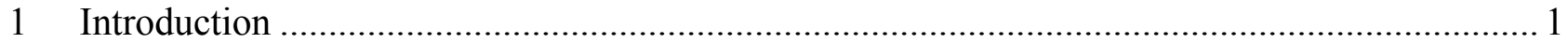

2 Evaluating the Principal-Agent Problem in U.S. Commercial Buildings ............................... 2

3 Assessing the PA Problem for Space Conditioning in U.S. Commercial Buildings.................. 8

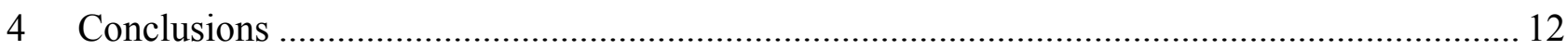

Figure 1: Average energy consumption per served floor space per building degree-day across type of occupancy and according to building subsamples (Btu/sqft.dd) ......................................... 9

Figure 2: Higher space conditioning end-use energy consumption due to the usage PA problem ... 14

\section{Tables}

Table 1: Principal-Agent Classification of Energy End-users for the Residential Sector ................. 3

Table 2: PA Classification in the Context of Commercial Buildings with Central Equipment ${ }^{\text {(a) }} \ldots . . . .3$

Table 3: Profiles of Some CBECS 2003 Subsamples................................................................ 6

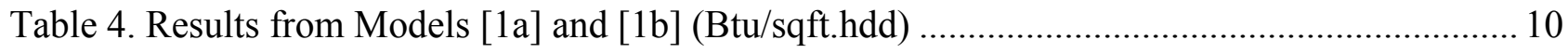

Table 5. Results from Models [1a] and [1b] (Btu/sqft.hdd) ................................................... 10

Table 6. Results from Model [1b] for Different Ranges of Building Area................................... 10

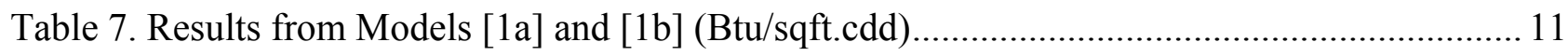

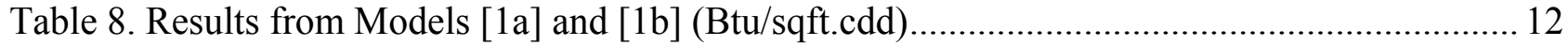

Table 9. Results from Model [1b] for Different Census Divisions............................................. 12 


\section{Introduction}

Building energy consumption and associated emissions are growing fast, due to the rapid expansion of both building area and increased ownership of energy-consuming equipment (IEA 2008). Energy is used in buildings to provide a variety of services such as space heating and cooling, water heating, lighting, refrigeration, and electricity for electronics and other equipment (Koomey et al. 2001). However, due to numerous market failures and barriers, buildings are seldom built to use energy efficiently, in spite of the significant costs that inefficiency imposes on consumers and the nation (Brown 2001).

Market failures occur whenever there is a flaw in the way markets operate, violating the (neoclassical) economic assumptions defining an ideal market. One such failure affecting energy use is the misplaced incentives that prevent energy-efficient investments and lead to the so-called energy efficiency gap. The issue is recognized as a principal-agent problem ${ }^{2}$ (PA problem). In energy efficiency, the PA problem occurs whenever "an agent has the authority to act on the behalf of a consumer, but does not fully reflect the consumer's best interests" (Brown, 2001). The matter has been extensively discussed in the literature. ${ }^{3}$ In the buildings sector, for example, the (energyefficiency) PA problem was quantitatively addressed for residential buildings by Baardsen (2007), Joosen et al. (2007), and Murtishaw and Sathaye (2006), and for office buildings by Bjorndalen and Bugge (2007), Takahashi and Asano (2007), and Visser and Harmelink (2007).

Barriers to energy efficiency can be found in equipment design and supply, diffusion, and operation. In the first case, industry may lack incentives to manufacture efficient devices if they are not marketable to large segments in the market. In the case of diffusion, barriers may exist because "if the potential adopter is not the party that pays the energy bill, then good information in the hands of the potential adopter may not be sufficient for optimal diffusion; adoption will occur only if the adopter can recover the investment from the party that enjoys the energy savings" (Jaffe and Stavins 1994b). In the case of operation, barriers can occur whenever the energy bill is paid indirectly, and the energy user has no information regarding the actual energy he or she has been consuming, thus lacking incentives to do so efficiently. Therefore, in energy efficiency, the PA problem comes from the lack of both information symmetry and incentives to act accordingly. In buildings, it is related to the decision-making on purchase and operation of energy-using equipment.

According to Brown (2001), landlords have no incentives to invest in energy-efficient equipment if the energy bill is to be paid by tenants (unless the latter "are aware of and express their selfinterest"), while tenants have no incentives to use energy efficiently if they are not (directly) paying the energy bill but landlords are. These are the assumptions considered by Bjorndalen and Bugge (2007), Takahashi and Asano (2007), and Visser and Harmelink (2007) to straightforwardly quantify the extent of the PA problem in office buildings located in, respectively, Norway, Japan, and the Netherlands. As reported, in Japan and in the Netherlands there is no relevant difference in

${ }^{2}$ The principal-agent problem (or agency dilemma) in economics refers to the potential difficulties arising when two parties engaged in a contract have different goals and levels of information (IEA 2007b).

${ }^{3}$ See for example Koomey (1990), DeCanio (1993), Howarth and Andersson (1993), Jaffe and Stavins (1994a, 1994b), Levine et al. (1994), Howarth et al. (2000), Sorrell et al. (2000), Brown (2001), Meier and Eide (2007) and IEA (2007a). 
energy consumption between owner-occupied and leased offices. Takahashi and Asano (2007) also report that "energy use per square meter is about 33\% higher in energy-cost-not-included rental office space than in energy-cost-included rental offices." Jewell (2002, apud Reed et al. 2004) notices that energy-efficiency improvements can increase asset value, which is of substantial benefit to landlords, but Koomey (1990) argues that efficiency increases asset value only if there is a standardized rating system for estimating building energy consumption prior to its occupation. Reed et al. (2004), while studying the 1999 commercial new construction market, ${ }^{4}$ found that, in some lease situations, lessees may be a more important decision-maker in new constructions than the person who physically owns the structure. They additionally argue that "the notion that the commercial sector is difficult to deal with because of split incentives may only be true for a very small percentage of commercial properties."

This work aims at quantitatively evaluating the existence of the PA problem in commercial buildings ${ }^{5}(\mathrm{CB})$ in the United States using statistical analysis. It estimates the higher end-use energy consumed due to the problem in selected building categories where the market failure seems to occur. The analysis relies on 2003 data from the last available Commercial Buildings Energy Consumption Survey (CBECS). CBECS is carried out by the U.S. Department of Energy (DOE) and is a "national sample survey that collects information on the stock of U.S. commercial buildings, their energy-related building characteristics, and their energy consumption and expenditures." The first such survey was conducted in 1979, and since 1995 it has been undertaken on a quadrennial basis (DOE, 2008a).

The report is organized into three parts. Section 2 presents the general approach adopted to identify and locate the PA problem in CB, as well as the data sources and methodology employed. Section 3 analyzes the existence of the PA problem in CB (in the U.S., 2003) space heating and cooling. Section 4 summarizes the results.

\section{Evaluating the Principal-Agent Problem in U.S. Commercial Buildings}

\section{IDENTIFYING AND LOCATING THE PA PROBLEM IN CB}

There are three roles that landlords and tenants can play concerning energy-using equipment in buildings: the decision-maker, who decides what equipment to install; the user, who operates the equipment; or the payer, who pays for the energy consumed. A PA problem may exist whenever the payer is not the same agent as the decision-maker or the user. In the first case, the decision-maker may not have an incentive to install energy efficient equipment; in the second, the user may not have an incentive to use equipment efficiently. ${ }^{6}$ The market failure can also occur when the user is neither the landlord nor the tenant but a third party, as is the case in buildings with lodging, inpatient health care, or temporary business offices (short-term rental). In this case, since energy costs are recovered from the service rate, there may not be incentives to install energy-efficient

\footnotetext{
${ }^{4}$ The study aimed at better understanding the needs and operation of the market, as well as at identifying needed technologies and effective strategies for technology diffusion.

${ }^{5}$ Commercial buildings refer to "all buildings in which at least half of the floor space is used for a purpose that is not residential, industrial, or agricultural, and includes building types that might not traditionally be considered "commercial," such as schools, correctional institutions, and buildings used for religious worship" (DOE, $2008 \mathrm{a})$.

${ }^{6}$ We do not account for differences in either building physical characteristics or facilities operation that could also influence building energy efficiency.
} 
equipment; similarly, since energy costs are embedded in the rent, there may not be incentives to use equipment efficiently.

Murtishaw and Sathaye (2006) classify residential energy end-users in four categories, according to whether they can choose (or not) the energy end-use device and directly or indirectly pay for the energy consumed (see Table 1). According to such classification, the PA problem will not occur only when an energy end-user can choose the device and pays directly for the energy consumption, in which case he or she has a clear incentive to both install energy-efficient equipment and operate it efficiently. ${ }^{7}$ In the other three cases, the PA market failure may or may not occur depending on certain specific conditions.

Considering commercial buildings, the three cases where the PA problem may occur can be associated with some building occupancy and equipment characteristics, such as the number of businesses in the building (single or multiple businesses), the type of occupancy (owner-occupied, non-owner-occupied, or mixed), the installation mode of adopted equipment (room-based or centrally installed in floor/building), and the responsibility for selecting the equipment (ownerprovided or tenant-installed). Table 2 relates these four building properties with the four PA cases in Table 1 for centrally installed equipment.

Table 1: Principal-Agent Classification of Energy End-users for the Residential Sector

\begin{tabular}{|l|l|l|}
\hline & \multicolumn{1}{|c|}{ Can Choose Device } & \multicolumn{1}{c|}{ Cannot Choose Device } \\
\hline Direct Energy Payment & Case N: No PA problem & Case E: Efficiency problem \\
\hline Indirect Energy Payment & Case B: Both Usage \& Efficiency Problem & Case U: Usage problem \\
\hline
\end{tabular}

Source: Murtishaw and Sathaye (2006)

Table 2: PA Classification in the Context of Commercial Buildings with Central Equipment ${ }^{(a)}$

\begin{tabular}{|c|c|c|c|c|}
\hline \multicolumn{3}{|r|}{ Building } & \multicolumn{2}{|c|}{ Central Equipment } \\
\hline Business & \multicolumn{2}{|c|}{ Occupancy } & Owner provided & Tenant installed \\
\hline \multirow{2}{*}{ Single } & \multicolumn{2}{|c|}{ Owner } & $\mathbf{N}$ & - \\
\hline & \multicolumn{2}{|c|}{ Non-owner } & $\mathbf{E}, \mathrm{U}^{(\mathrm{b})}$ & $\mathrm{N}^{(\mathrm{c})}$ \\
\hline \multirow{4}{*}{ Multiple $^{(\mathrm{d})}$} & \multicolumn{2}{|c|}{ Owner only } & $\mathrm{B}$ & - \\
\hline & \multicolumn{2}{|c|}{ Non-owner only } & $\mathbf{U}$ & $\mathrm{B}$ \\
\hline & \multirow{2}{*}{ Mixed } & Owner occupied units & $\mathrm{B}$ & - \\
\hline & & Non-owner occupied units & $\mathrm{U}$ & - (e) \\
\hline
\end{tabular}

(a) Bold lettering indicates the cases studied in this work.

(b) An efficiency problem may exist when the tenant directly pays the energy bill and a usage problem when energy cost is either part of the rent or charged separately yet as a flat rate.

(c) Assumes that, in single-occupied buildings, if tenant can choose the device he/she is also responsible for direct energy payment.

(d) Assumes that energy consumption by central equipment in multi-business buildings is not individually metered.

(e) Considering that central equipment is always provided by owners in buildings with mixed occupancy.

${ }^{7}$ The non-existence of the PA problem, however, does not imply that the efficient option will be chosen, since the end user may, for any other reason, rely on a less efficient device. 
Whenever a tenant utilizes landlord-provided equipment, a PA problem may occur. If the tenant is individually metered and he/she pays the corresponding energy bill, an efficiency problem can exist (Case E, Table 2). On the other hand, if the tenant is not individually metered but indirectly pays for energy cost, a usage problem can exist (Case U, Table 2). Additionally, both efficiency and usage problems can occur in multi-business buildings whenever owner- or non-owner-occupied units share centrally installed equipment provided by themselves (Case B, Table 2). However, this last case does not represent a split incentive between landlords and tenants, but rather among landlords or tenants, and is out of the scope of this study. Efficiency and usage problems may also potentially arise in buildings with business activities associated with short-term rentals, regardless of the number of businesses in the building, type of building occupancy and equipment installation, and responsibility for providing the equipment. Yet, due to the lack of data representing a counterfactual situation to be compared to, those cases are not quantifiable - and therefore not considered - in this study.

The energy-efficiency PA market failure can be evaluated from estimating the difference between the energy required to provide a unit of space-conditioning energy service (end-use energy intensity, EUI) in non-owner-occupied versus owner-occupied buildings: A positive difference in EUI (higher non-owner-occupied building EUI) would indicate either that landlord-provided equipment in non-owner-occupied buildings is less efficient than the ones owners usually adopt for themselves (efficiency problem), or that energy-using equipment has similar efficiency but is misused by tenants (usage problem). In order to eliminate potential distortions in the analysis due to cases where tenants would accept a lower level of energy service because of the higher energy costs imposed by the use of non-efficient, landlord-provided equipment, we adopt a degree-days adjusted EUI. It normalizes the commonly used EUI, based on energy consumption per floor space, to building temperature increase or decrease along the year. The feasibility of evaluating the market failure, therefore, depends on the availability of data regarding the end-use energy consumption and its corresponding amount of physical energy service provided, as well as the four pieces of information necessary to characterize each PA case according to Table 2.

\section{DATA SOURCES}

This study relies on CBECS 2003 public micro data (DOE, 2006a) ${ }^{8}$ as the sole source for all of the information required. The survey indeed provides all of the necessary information but gives no indication of who (landlord or tenant) selected the equipment and who (landlord or tenant) pays the energy bill. The responsibility for selecting installed equipment is then treated according to the installation characteristic of existing equipment (room-based or floor/building central) and under two different assumptions. In the case of room-based equipment, it could be either landlordprovided or tenant-installed and therefore not inferable in the absence of any additional information or assumption. Yet, considering that tenants can replace landlord-provided, non-efficient roombased equipment (which is assumed to be economically attractive), buildings served by this type of equipment would not represent an instance of the PA problem (Case N, Table 1). On the other hand, installing or replacing either floor or building central equipment may involve a payback time longer than tenants would typically be willing to wait for; this type of equipment is therefore assumed to be always provided by landlord and thus a prospective source of the market failure (Cases E and U, Table 1).

\footnotetext{
${ }^{8}$ Including the end-use estimates posted in 2008.
} 
Eligible energy end-uses to be assessed are therefore space conditioning ${ }^{9}$ and water heating; however, the latter lacks any information related to the physical amount of energy service provided $^{10}$ and hence is not quantitatively assessable. The issue of who pays the energy bill would be useful only to differentiate cases $E$ and $U$ in single-business, non-owner occupied buildings with landlord-provided centrally installed equipment (see Table 2). However, since there is only one tenant in the building, it is assumed he/she pays utilities and therefore the only potential type of market failure in this case is the efficiency problem.

Checking for both the efficiency and usage PA problems requires a reference set of buildings where the market failure is assumed not to exist, and two other sets where each type of the problem is expected to occur. The reference set provides a benchmark EUI, to which EUIs of the other two sets are compared. The study concentrates on the sets of single-owner, single-non-owner, and multitenant occupied buildings, served by centrally installed equipment (as highlighted in Table 2). The single-owner occupied set of buildings, where equipment and facilities are supposedly energyefficient and efficiently operated, is selected as the reference one. The other two sets of buildings where the PA problem is evaluated are the single-tenant-occupied ones, for the efficiency problem, and the multi-tenant for the usage problem (see highlights in Table 2).

Two pairs of CBECS subsamples are used to evaluate each type of PA problem in space heating and cooling. The efficiency problem is assessed over the set of single-owner and single-tenant-occupied buildings served only by centrally installed heating $\left(B_{\text {hsost }}\right)$ and cooling $\left(B_{\text {csost }}\right)$ equipment. The usage problem is evaluated over the set of single-owner and multi-tenant occupied buildings served only by centrally installed heating $\left(B_{\text {hsomt }}\right)$ and cooling $\left(B_{\text {csomt }}\right)$ equipment. These four building subsamples represent the $\mathrm{CB}$ subsectors where the market failure can be more accurately evaluated: In single-owner occupied buildings, the only user of the equipment is also both the one who decided about it and the one who directly pays for its energy consumption (Case N, Table 1); in singletenant-occupied buildings, the only user of the equipment, despite not having selected it (as assumed), pays directly for its energy consumption (Case E, Table 1); in multi-tenant occupied buildings, none of the users decided about the equipment, neither (as assumed) are they metered for the end-use consumption, yet they indirectly pay for it (Case U, Table 1). Table 3 depicts building physical and energy-consuming-related properties for some CBECS 2003 subsamples-from the comprehensive non-government, non-mall buildings subsample to the four very specific subsamples used in this study (shown in bold in the Table).

\section{$\underline{\text { METHODOLOGY }}$}

In CBECS 2003, end-use consumption is estimated (mainly) based on both building physical characteristics and "average estimates for equipment efficiency" (DOE, 2008c). Therefore, any difference in energy efficiency between non-owner- and owner-occupied buildings could arise only from differences in equipment selection or usage, or from any other building (physical or operational) characteristics that could significantly influence building energy performance. The latter however is not considered in this work.

\footnotetext{
${ }^{9}$ Meier and Eide (2007) also recognize commercial building HVAC expenses as a PA problem.

${ }^{10}$ Unlike space conditioning, for which CBECS indicates the extent of served (heated and cooled) area, as well as the (heating and cooling) degree-days, there is no piece of surveyed information that could be used as a proxy for the volume of heated water.
} 
Hence the existence of the efficiency PA problem is associated with decisions made on equipment selection and the usage PA problem with equipment operation.

Table 3: Profiles of Some CBECS 2003 Subsamples

\begin{tabular}{|c|c|c|c|c|c|c|c|c|}
\hline \multirow{2}{*}{ Sample ${ }^{\text {(a) }}$} & \multirow{2}{*}{$\begin{array}{l}\text { \#Obser- } \\
\text { vations }\end{array}$} & \multirow{2}{*}{$\begin{array}{l}\text { \#Bld } \\
\text { (th) }\end{array}$} & \multicolumn{2}{|c|}{ Area (mi sqft) } & \multirow{2}{*}{$\begin{array}{l}\text { Degree } \\
\text { Days }^{(b)}\end{array}$} & \multirow{2}{*}{$\begin{array}{l}\text { Operating } \\
\text { Level }^{(c)}\end{array}$} & \multicolumn{2}{|c|}{ Energy (tri Btu) } \\
\hline & & & Total & Served & & & Total & End-Use $^{(\mathrm{d})}$ \\
\hline $\begin{array}{l}\text { All non-government, } \\
\text { non-mall buildings }\end{array}$ & 3522 & 3643 & 44069 & & & 0.373 & 3946 & \\
\hline Owner-occupied & 1762 & 1793 & 21904 & & & 0.349 & 1921 & \\
\hline Non-owner-occupied & 1760 & 1849 & 22165 & & & 0.396 & 2024 & \\
\hline \multicolumn{9}{|l|}{ Buildings with space heating } \\
\hline Any type of equipment & 3169 & 3055 & 40078 & 35091 & 4666 & 0.378 & 3797 & 1329 \\
\hline Owner-occupied & 1605 & 1548 & 20142 & 17912 & 4903 & 0.352 & 1852 & 723 \\
\hline Non-owner-occupied & 1564 & 1507 & 19936 & 17179 & 4422 & 0.405 & 1945 & 606 \\
\hline With central equipment & 2710 & 2486 & 35240 & 31171 & 4864 & 0.376 & 3493 & 1287 \\
\hline Owner-occupied & 1398 & 1270 & 17912 & 16058 & 5120 & 0.360 & 1727 & 705 \\
\hline Non-owner-occupied & 1312 & 1217 & 17328 & 15113 & 4597 & 0.393 & 1766 & 582 \\
\hline Only central equipment & 1989 & 1974 & 24675 & 21654 & 4773 & 0.372 & 2473 & 936 \\
\hline Owner-occupied & 1012 & 987 & 12405 & 11039 & 5032 & 0.354 & 1170 & 476 \\
\hline Non-owner-occupied & 977 & 988 & 12271 & 10615 & 4515 & 0.390 & 1303 & 460 \\
\hline $\begin{array}{l}\text { Single-owner or single- } \\
\text { tenant }\left(B_{\text {hsost }}\right)\end{array}$ & 1450 & 1581 & 17503 & 15185 & 4831 & 0.377 & 1816 & 691 \\
\hline Owner-occupied & 732 & 748 & 8539 & 7490 & 5080 & 0.358 & 803 & 331 \\
\hline Non-owner-occupied & 718 & 833 & 8965 & 7695 & 4607 & 0.393 & 1013 & 359 \\
\hline $\begin{array}{l}\text { Single-owner or multi-tenant } \\
\left(B_{\text {hsomt }}\right)\end{array}$ & 991 & 902 & 11845 & 10409 & 4898 & 0.361 & 1092 & 431 \\
\hline Owner occupied & 732 & 748 & 8539 & 7490 & 5080 & 0.358 & 803 & 331 \\
\hline Non-owner occupied & 259 & 154 & 3306 & 2920 & 4016 & 0.374 & 289 & 100 \\
\hline \multicolumn{9}{|l|}{ Buildings with space cooling } \\
\hline Any type of equipment & 3160 & 3043 & 40101 & 28721 & 1417 & 0.380 & 3709 & 283 \\
\hline Owner-occupied & 1585 & 1537 & 20031 & 14167 & 1340 & 0.356 & 1781 & 138 \\
\hline Non-owner-occupied & 1575 & 1505 & 20070 & 14553 & 1495 & 0.405 & 1929 & 145 \\
\hline With central equipment & 2558 & 2267 & 33188 & 24204 & 1429 & 0.381 & 3239 & 239 \\
\hline Owner-occupied & 1306 & 1134 & 16602 & 12101 & 1331 & 0.369 & 1581 & 121 \\
\hline Non-owner-occupied & 1252 & 1133 & 16586 & 12102 & 1527 & 0.393 & 1658 & 117 \\
\hline Only central equipment & 2011 & 1975 & 25214 & 18278 & 1444 & 0.374 & 2402 & 183 \\
\hline Owner-occupied & 1015 & 979 & 12568 & 9143 & 1340 & 0.364 & 1153 & 90 \\
\hline Non-owner-occupied & 996 & 996 & 12646 & 9135 & 1546 & 0.384 & 1249 & 93 \\
\hline $\begin{array}{l}\text { Single-owner or single- } \\
\text { tenant }\left(B_{\text {csost }}\right)\end{array}$ & 1418 & 1575 & 17283 & 12124 & 1420 & 0.38 & 1697 & 115 \\
\hline Owner-occupied & 716 & 751 & 8468 & 5959 & 1305 & 0.366 & 760 & 53 \\
\hline Non-owner-occupied & 702 & 824 & 8814 & 6166 & 1525 & 0.393 & 938 & 62 \\
\hline $\begin{array}{l}\text { Single-owner or multi-tenant } \\
\left(B_{\text {csomt }}\right)\end{array}$ & 1010 & 923 & 12300 & 8928 & 1368 & 0.362 & 1071 & 84 \\
\hline Owner-occupied & 716 & 751 & 8468 & 5959 & 1305 & 0.366 & 760 & 53 \\
\hline Non-owner-occupied & 294 & 172 & 3832 & 2969 & 1644 & 0.344 & 311 & 31 \\
\hline
\end{tabular}

(a) Highlights refer to samples where the PA problem is assessed.

(b) Heating degree-days (HDD) in buildings with space heating, and cooling degree-days (CDD) in buildings with space cooling.

(c) Fraction of the year that building was operational.

(d) Estimated end-use energy for space heating in buildings with space heating and space cooling in buildings with space cooling. 
For each of the space conditioning end-uses, the two types of PA problems are assessed from: (a) estimating EUIs in owner- and non-owner-occupied buildings; (b) evaluating the potential higher energy consumption from the PA problem. The details of these two steps are as follows:

\section{Estimating EUIs in owner- and non-owner-occupied buildings}

Our analysis relies on two drivers of energy consumption for space conditioning: The building conditioned (volumetric) space and its internal time-integrated temperature change. They represent — other factors being equal — the main factors demanding more or less energy to keep building internal temperature at the standard level of $65^{\circ} \mathrm{F}$. None of this information however is available in CBECS 2003; thus we adopt two proxies for them: the building (heating or cooling) served floor space, ${ }^{11}$ and its local degree-days adjusted to its operating level (henceforth denominated building degree-days). ${ }^{12}$ The estimated EUIs therefore refer to the space conditioning end-use energy consumed $(E U C)$ per served floor space (ServedArea) per building degree-days $(B d l D D)$. They are estimated for different building categories from the following regression model:

$$
E U C=E U I \cdot(\text { ServedArea } \cdot \text { BldDD })+\varepsilon
$$

Model [1a], when (separately) applied to owner- and non-owner-occupied buildings, may result in different EUI estimates that are individually statistically significant. However, different statistically significant EUIs do not imply a statistically significant difference. The difference between non-owner- and owner-occupied building EUIs is therefore statistically estimated from extending model [1a] with a new term. The appended term is formed by the interaction of the former main term with a dummy variable $(o)$ representing the building type of occupancy ( 0 for owner-occupied, 1 for non-owner-occupied):

$$
E U C=E U I_{b} \cdot(\text { ServedArea } \cdot B l d D D)+E U I^{\prime} \cdot(o \cdot \text { ServedArea } \cdot B l d D D)+\varepsilon
$$

Model [1b] is designed to capture in the coefficient EUI' the higher EUI of non-owner-occupied buildings when compared to owner-occupied ones. While energy consumed in owner-occupied buildings is allocated only in the first term $\left(o_{\text {owner }}=0\right)$, consumption in non-owner-occupied ones is distributed across the first and the second terms, the latter ultimately representing the energy consumption associated to the simple fact that they are non-owner-occupied.

Models [1a] and [1b] are used to assess both the efficiency and usage PA problems. In the first case, however, because CBECS estimates for end-use consumption were developed based on average equipment efficiency, in case of market failure we further (a) estimate EUIs for each type of (heating or cooling) equipment (regardless of building type of occupancy); (b) estimate the equipment mix $^{13}$ in owner- and non-owner-occupied buildings; and (c) verify whether a difference in the EUIs of those buildings could be explained by relevant differences in their corresponding equipment mix.

${ }^{11}$ Calculated after the building total area and the percentage of (heated or cooled) served area.

12 Calculated after building local degree-days, the number of months it was used in the previous 12 months, and its weekly operating hours.

13 The mix is expressed by the share of the space-conditioning service (served floor space times time-integrated temperature change) that is provided by each type of equipment, in reference to the total space-conditioning service provided to the building. 
Regression models [1a] and [1b] are weighted by the final full sample building weight $\left(w_{i}\right) .^{14}$ They also have been intentionally designed with zero intercept in order to guarantee zero enduse consumption in the absence of the drivers. Further, to make results comparable, differences between non-owner- and owner-occupied building EUIs are also expressed in relative values. EUI relative differences are calculated as:

$$
\Delta E U I_{\text {rel }}=\frac{\left(E U I_{\text {non-owner }}-E U I_{\text {owner }}\right)}{E U I_{\text {owner }}}=\frac{E U I^{\prime}}{E U I_{b}}
$$

The PA problem is supposed to exist whenever $\Delta E U I_{\text {rel }}$ is positive. ${ }^{15}$ The measure also denotes the magnitude of the problem, with higher relative differences indicating a more critical market failure.

\section{Evaluating the potential higher energy consumption from the PA problem}

The potential higher energy consumption (HigherEnergy) due to the PA problem is evaluated after the (statistically significant) estimated positive EUI differences. It is calculated as a percentage of the total end-use energy consumed to provide the corresponding energy service (space heating or cooling) in the non-owner-occupied buildings affected by the market failure. The percentage is given by the proportion of the estimated EUI difference in relation to the EUI estimated for non-owner-occupied buildings:

$$
\text { HigherEnergy }=\frac{E U I^{\prime}}{E U I_{b}+E U I^{\prime}} \cdot E U C
$$

Values are reported along with a 95\% confidence interval, according to the statistical distributions of the estimated positive EUI differences.

\section{Assessing the PA Problem for Space Conditioning in U.S. Commercial Buildings}

Figure 1 presents weighted averages ${ }^{16}$ of end-use consumption per served (heated and cooled) floor space per building degree-day, according to building type of occupancy and across selected samples. As can be observed from the three leftmost $x$-categories, non-owner-occupied buildings consume more end-use energy per unit of served floor space and degree-day than the owneroccupied ones. In the case of space heating, the more the samples concentrate on buildings served by centrally installed equipment, the higher the unitary energy consumption. The relation is also true when comparing single-owner-occupied to single-tenant-occupied buildings, and suggests the existence of the efficiency PA problem in both space heating and cooling. On the other hand, when comparing single-owner-occupied to multi-tenant-occupied buildings, we find an opposite relation, suggesting the non-existence of the usage PA problem. We develop the statistical analysis described above (Methodology) to evaluate to what extent those findings hold.

\footnotetext{
${ }^{14}$ In CBECS, it indicates, for each sampled building, the number of actual ones it represents.

${ }^{15}$ The PA problem is highlighted with bold $\Delta E U I_{r e l}$ values.

${ }^{16}$ Calculated as: $E U I=\sum_{i}\left(w_{i} \cdot E U I_{i}\right) / \sum_{i} w_{i}$, where $E U I_{i}=E U C_{i} /\left(\right.$ ServedArea $_{i} \cdot$ BldDD $\left._{i}\right)$
} 


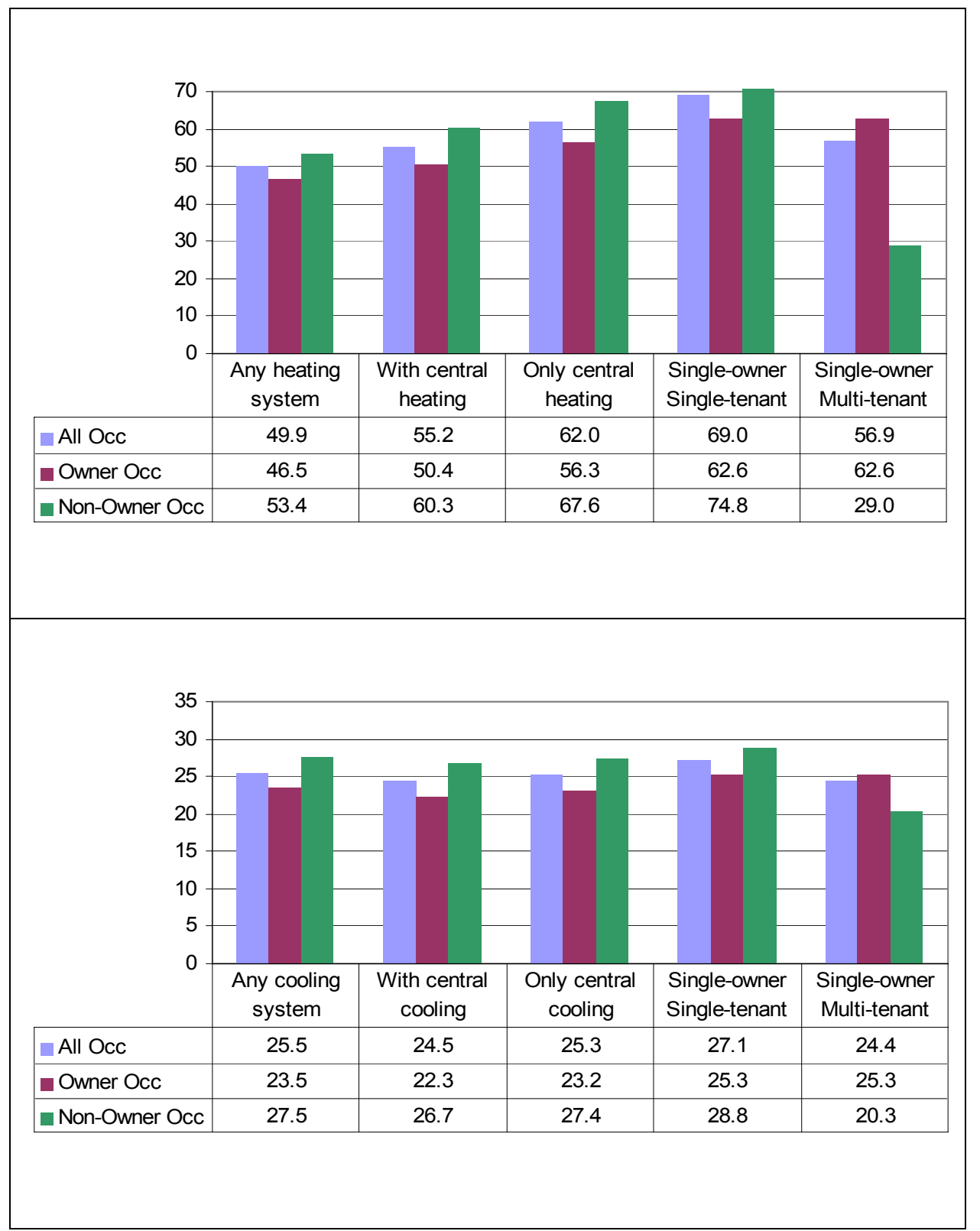

Figure 1: Average energy consumption per served floor space per building degree-day across type of occupancy and according to building subsamples (Btu/sqft.dd)

\subsection{The PA Problem in Space Heating}

\section{$\underline{\text { ASSESSING THE EFFICIENCY PA PROBLEM }}$}

Model [1a], when individually evaluated over single-owner and single-tenant-occupied buildings, suggests that the market failure may not exist since the EUI of single-tenant-occupied buildings is lower than the single-owner ones (see Table 4). Model [1b] confirms that the negative difference between EUIs is statistically significant. The efficiency PA problem therefore does not exist for this set of non-owner-occupied buildings. 
Table 4. Results from Models [1a] and [1b] (Btu/sqft.hdd)

\begin{tabular}{|l|c|l|l|l|}
\hline \multirow{2}{*}{ Sample } & Model [1a] & \multicolumn{3}{|c|}{ Model [1b] } \\
\cline { 2 - 5 } & $E U I$ & $E U I_{b}$ & $E U I^{\prime}$ & \multicolumn{1}{|c|}{$\Delta E U I_{r e l}$} \\
\hline Single-Owner & $12.9(0.000)$ & - & - & - \\
\hline Single-Tenant & $11.0(0.000)$ & - & - & - \\
\hline All Occupancies & $11.9(0.000)$ & $12.9(0.000)$ & $-1.8(0.005)$ & -0.14 \\
\hline
\end{tabular}

\section{ASSESSING THE USAGE PA PROBLEM}

Model [1a], individually evaluated over single-owner and multi-tenant-occupied buildings, indicates the market failure may not exist since the EUI of multi-tenant-occupied buildings is lower than the single-owner ones (see Table 5). Model [1b] confirms that the negative difference between EUIs is statistically significant. The usage PA problem therefore does not exist for this set of non-owneroccupied buildings. A deeper analysis of the samples however shows that the non-existence of the PA problem is related to building size. Table 6 summarizes the results found after evaluating model [1b] over different ranges of building area.

Table 5. Results from Models [1a] and [1b] (Btu/sqft.hdd)

\begin{tabular}{|l|l|l|l|l|}
\hline \multirow{2}{*}{ Sample } & Model [1a] & \multicolumn{4}{|l|}{ Model [1b] } & \multicolumn{2}{l|}{} \\
\cline { 2 - 5 } & $E U I$ & $E U I_{b}$ & EUI' & $\Delta E I_{\text {rel }}$ \\
\hline Single-Owner & $12.9(0.000)$ & - & - & - \\
\hline Multi-Tenant & $9.5(0.000)$ & - & - & - \\
\hline All Occupancies & $12.1(0.000)$ & $12.9(0.000)$ & $-3.4(0.003)$ & -0.26 \\
\hline
\end{tabular}

Table 6. Results from Model [1b] for Different Ranges of Building Area

\begin{tabular}{|l|l|l|l|}
\hline Building Area & $E U I_{b}$ & $E U I^{\prime}$ & $\Delta E U I_{\text {rel }}$ \\
\hline$\leq 50 \mathrm{k} \mathrm{sq} . \mathrm{ft}$. & $15.5(0.000)$ & $4.9(0.022)$ & $\mathbf{0 . 3 2}$ \\
\hline $50<\ldots<600 \mathrm{k}$ sq. ft. & $11.6(0.000)$ & $-0.5(0.841)$ & \\
\hline$\geq 600 \mathrm{k} \mathrm{sq} . \mathrm{ft}$. & $17.7(0.000)$ & $-10.7(0.008)$ & -0.61 \\
\hline
\end{tabular}

The above results indicate that the non-existence of the PA problem can be asserted only for buildings larger than 600,000 sq. $\mathrm{ft}$. For buildings smaller than 50,000 sq. $\mathrm{ft}$. the market failure is clearly observed and may be related to differences in equipment mix or operation. The weighted average $\mathrm{EUI}^{17}$ of the equipment mix is roughly the same in both types of buildings, and we thus discard the effects that a different share in equipment usage could have on EUI differences. Therefore, the market failure is a usage PA problem.

\footnotetext{
${ }^{17}$ Calculated from EUIs estimated for each type of equipment in these buildings, and weighted by their respectively share of heating service provided.
} 


\section{EVALUATING THE POTENTIAL HIGHER ENERGY CONSUMPTION FROM THE PA PROBLEM}

We found no statistical evidence of the existence of the efficiency PA problem in space heating. Concerning the usage PA problem, despite the non-existence of the market failure at the aggregate level, it can be asserted for small ( $\leq 50,000 \mathrm{sq}$. ft.) buildings - though not all of the small ones, but the very specific subset of small, non-government, non-mall, multi-tenant-occupied buildings heated only by floor or building centrally installed equipment.

Based on 2003 data, the market failure would thus affect 141,000 buildings, with a total of 1.518 billion sq. ft. The extent of the problem, quantified from the estimated higher EUI of non-owneroccupied buildings in reference to the owner occupied ones, could have led to an additional site energy consumption of $12.3( \pm 10.5)$ trillion $\mathrm{Btu},{ }^{18}$ corresponding to $24.0 \%( \pm 20.5 \%)$ of space heating and $10.2 \%( \pm 8.7 \%)$ of total site energy consumed in those buildings. This represents $0.31 \%$ $( \pm 0.27 \%)$ and $0.19 \%( \pm 0.16 \%)$ of total site energy consumed, respectively, in non-government, nonmall buildings and in all U.S. commercial buildings.

\subsection{The PA Problem in Space Cooling}

\section{ASSESSING THE EFFICIENCY PA PROBLEM}

Model [1a], when individually evaluated over single-owner and single-tenant-occupied buildings, suggests that the market failure may not exist since the EUI of single-tenant-occupied buildings is lower than the single-owner ones (see Table 7). Model [1b] confirms that the negative difference between EUIs is statistically significant. The efficiency PA problem therefore does not exist for this set of non-owner-occupied buildings.

Table 7. Results from Models [1a] and [1b] (Btu/sqft.cdd)

\begin{tabular}{|l|l|l|l|l|}
\hline \multirow{2}{*}{ Sample } & Model [1a] & \multicolumn{4}{l|}{ Model [1b] } \\
\cline { 2 - 5 } & $E U I$ & $E U I_{b}$ & EUI' & $\Delta E U I_{\text {rel }}$ \\
\hline Single-Owner & $10.3(0.000)$ & - & - & - \\
\hline Single-Tenant & $6.3(0.000)$ & - & - & - \\
\hline All Occupancies & $8.1(0.000)$ & $10.3(0.000)$ & $-4.0(0.000)$ & -0.39 \\
\hline
\end{tabular}

Assessing the Usage PA Problem

Model [1a], individually evaluated over single-owner and multi-tenant occupied buildings, indicates the market failure may exist since the EUI of multi-tenant occupied buildings is higher than the single-owner ones (see Table 8). Model [1b] confirms that the positive difference between EUIs is statistically significant. The usage PA problem therefore does exist for this set of non-owner occupied buildings. A deeper analysis (model [1b]) of the sample over individual census divisions yields (statistically significant) results as shown in Table 9.

\footnotetext{
${ }^{18}$ Corresponding primary energy is $14.6( \pm 12.4)$ TBtu, calculated after site-source energy rates from EPA (2007).
} 
Table 8. Results from Models [1a] and [1b] (Btu/sqft.cdd)

\begin{tabular}{|l|l|l|l|l|}
\hline \multirow{2}{*}{ Sample } & Model [1a] & \multicolumn{4}{l|}{ Model [1b] } & \multicolumn{3}{l|}{} \\
\cline { 2 - 5 } & $E U I$ & $E U I_{b}$ & EUI' & $\Delta E I_{\text {rel }}$ \\
\hline Single-Owner & $10.3(0.000)$ & - & - & - \\
\hline Multi-Tenant & $14.0(0.000)$ & - & - & - \\
\hline All Occupancies & $11.8(0.000)$ & $10.3(0.000)$ & $3.7(0.003)$ & 0.36 \\
\hline
\end{tabular}

Table 9. Results from Model [1b] for Different Census Divisions

\begin{tabular}{|l|l|l|l|}
\hline Census Division & $E U I_{b}$ & $E U I^{\prime}$ & $\Delta E U I_{\text {rel }}$ \\
\hline West North Central & $8.5(0.000)$ & $51.5(0.000)$ & 6.06 \\
\hline Mountain & $14.2(0.000)$ & $12.1(0.000)$ & 0.85 \\
\hline West South Central & $6.7(0.000)$ & $3.0(0.000)$ & 0.45 \\
\hline East South Central & $10.0(0.000)$ & $-4.5(0.003)$ & -0.45 \\
\hline East North Central & $29.1(0.000)$ & $-18.3(0.001)$ & -0.63 \\
\hline
\end{tabular}

The existence of the market failure in multi-tenant buildings is thus strongly influenced by the multi-tenant buildings located in the West North Central census division.

Evaluating the potential higher energy consumption from the PA problem

We found no statistical evidence of the existence of the efficiency PA problem in space cooling. Concerning the usage PA problem, despite the lower average energy consumption per floor space per building degree-day of single-owner-occupied buildings in comparison to multi-tenant-occupied ones (Figure 1), our statistical analysis suggests the existence of the market failure. The failure can be observed in the very specific subset of non-government, non-mall, multi-tenant-occupied buildings cooled only by floor or building centrally installed equipment.

Based on 2003 data, the market failure would thus affect 172,000 buildings, with a total of 3.832 billion sq. $\mathrm{ft}$. The extent of the problem, quantified from the estimated higher EUI of non-owneroccupied buildings in reference to the owner-occupied ones, leads to an additional site energy consumption of $8.3( \pm 4.0)$ trillion Btu, ${ }^{19}$ corresponding to $26.5 \%( \pm 12.7 \%)$ of space cooling and $2.7 \%( \pm 1.3 \%)$ of total site energy consumed in those buildings. This represents $0.21 \%( \pm 0.10 \%)$ and $0.13 \%( \pm 0.06 \%)$ of the total site energy consumed, respectively, in non-government, non-mall buildings and in all U.S. commercial buildings.

\section{Conclusions}

Energy use in buildings can be influenced by the presence of market failures, particularly due to the PA problem. This work quantitatively evaluates the occurrence of the problem in U.S. commercial buildings in 2003 for space conditioning end-use by assessing two hypotheses: centrally installed space-conditioning equipment in non-owner occupied buildings is (a) less energy-efficient than in corresponding owner-occupied ones, and/or (b) less efficiently operated whenever tenants are not directly responsible for paying the energy bill. Buildings energy efficiency is assessed through their end-use energy intensity, calculated as the ratio of end-use energy consumed per conditioned floor space per degree-day. The study focuses on the non-government, non-mall, and non-vacant subset of CBECS 2003 buildings served only by centrally installed space-conditioning equipment. This

${ }^{19}$ Corresponding primary energy is $25.5( \pm 12.2)$ TBtu, calculated after site-source energy rates from EPA (2007). 
last aspect of selected buildings relates to the assumption that (in general) tenants would not be willing or able to switch owner-provided centrally installed equipment (column "Cannot choose device," Table 1), but could do so with room-based devices.

The end-use consumption in CBECS 2003 is estimated considering average performances per type of equipment, and hence any difference between the energy efficiency of non-owner and owneroccupied buildings, as estimated from the survey, could arise from differences between equipment selection and/or usage, and for any other differences in physical or operational characteristics among those buildings (the latter issue however is not considered in this study). According to Table 1, this could lead to either an efficiency PA problem (Case E) or a usage PA problem (Case U).

The efficiency PA problem is evaluated by comparing EUIs of single-tenant and single-owneroccupied buildings, and verifying whether a statistically significant positive EUI difference could be explained by a relevant difference in the share of equipment used. The single-occupied buildings are chosen under the assumption that in such a subset of buildings, owners and tenants would directly pay the energy bill or, in the case of tenants, could at least be informed about what their energy consumption is. An efficient operation of energy-using devices is hence expected and a usage problem should not exist. Therefore, any difference between non-owner and owner-occupied building EUIs is related to differences in their equipment mix, since performance is assumed to be the same for each type of equipment.

The usage PA problem is evaluated by comparing EUIs of multi-tenant and single-owner (no tenant) occupied buildings. Such a subset of buildings is selected after the assumption that, in this case, while owners can directly relate their energy consumption to building energy cost, none of the tenants have access to the building energy bill, and neither can their share of building energy cost be associated with their actual consumption. A higher use of energy by centrally installed, nonindividually metered equipment is hence possible in the multi-tenant case. Relevant differences in equipment mix would as well influence building end-use energy intensity, and this is also accounted for $^{20}$ in order to assert the existence of a usage PA problem.

Based on the analysis, we conclude that there is no statistical evidence of the existence of the equipment efficiency PA problem in space heating and cooling. The non-existence of the equipment efficiency-related market failure is consistent with Reed et al. (2004), Takahashi and Asano (2007), and Visser and Harmelink (2007). It may be a consequence of improvements in energy standards, along with the fact that "remodeling and renovation activities are usually driven by a change in tenant and/or a tenant changing their operation." (Dohrmann et al. 2002). Hence, equipment replacement would be more frequent in non-owner-occupied buildings, and replacement devices are likely to be more efficient than the ones they replace.

Concerning the usage PA problem, our analysis shows that the market failure does exist. This is consistent with Takahashi and Asano's (2007) conclusion regarding office buildings in Japan. In the U.S., the problem can be noticed, for space heating, in smaller $(\leq 50,000$ sq. ft.) multi-tenant buildings. For space cooling, it can be observed at the aggregate level of multi-tenant buildings, and is strongly influenced by the ones located in West North Central census division.

\footnotetext{
${ }^{20}$ We evaluate the potential influence of equipment mix on EUI difference by comparing the usage share of each type of equipment in multi-tenant and single-owner-occupied buildings, in light of their (equipment) average performance.
} 
Figure 2 presents the higher end-use energy consumption due to the usage PA problem for space heating and cooling. The estimated higher energy consumption is conservative, since it applies only to the studied subset of U.S. commercial buildings. The extent of the problem could be broader if all non-owner-occupied buildings, served by both centrally installed and other types of heating and cooling equipment (not only the ones served solely by centrally installed equipment), were considered. This would expand the analysis, in the case of space heating, to 2.5 million buildings, encompassing 35.2 billion sq. $\mathrm{ft}$. and a total of 3.5 quads of end-use energy consumption. In the case of space cooling, the analysis would expand to 2.3 million buildings, encompassing 33.2 billion sq. $\mathrm{ft}$. and a total of 3.2 quads of end-use energy consumption. However, for those buildings, we are unable to disaggregate the building total end-use consumption into the energy consumed by centrally and non-centrally installed equipment, and thus not able to assess the existence of the market failure.

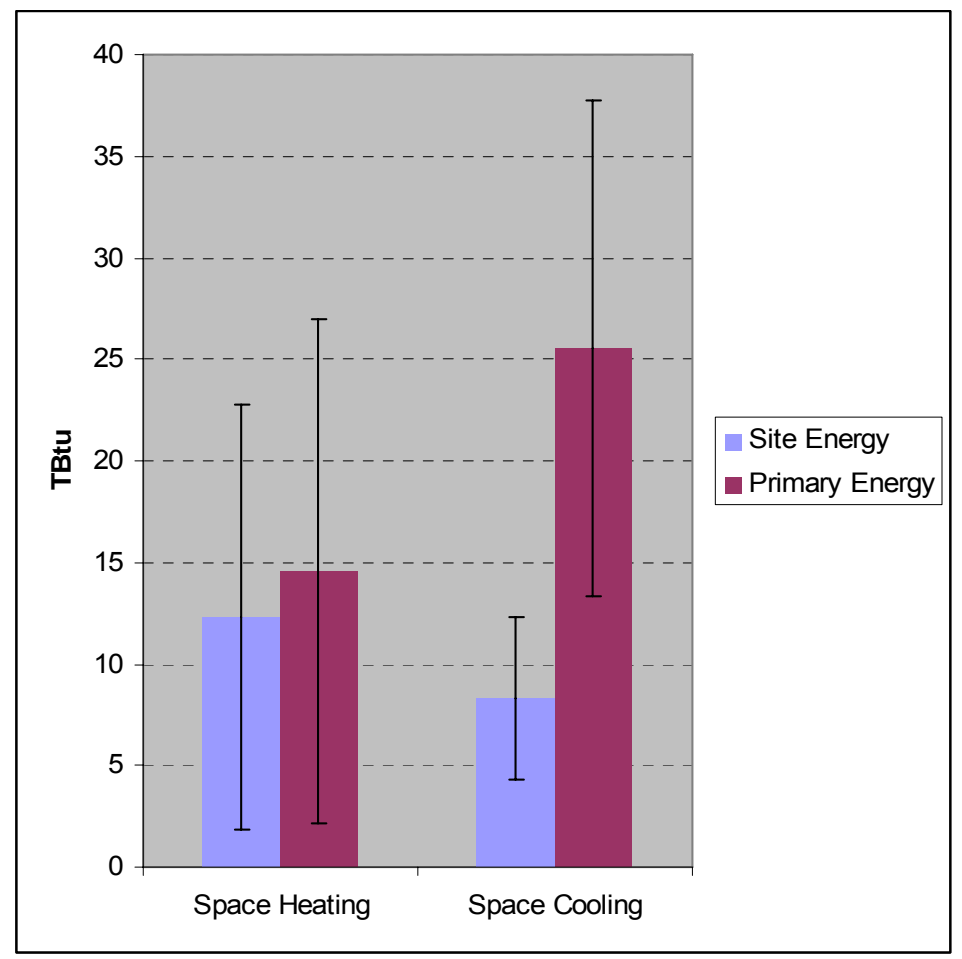

Figure 2: Higher space conditioning end-use energy consumption due to the usage PA problem

Study results are also limited by both lack of information and methodological issues regarding the estimation of end-use consumption in CBECS 2003. It would have been helpful, for example, if the survey had inquired whether, and to what extent, existing devices in non-owner-occupied buildings were provided by landlords. ${ }^{21}$ Likewise, models/methodologies used to estimate end-use consumption could also allow some variation in equipment performance across sampled buildings, while adjusting total energy consumed to the estimated energy services provided in the building, instead of relying exclusively on standard equipment performances.

${ }^{21}$ The more recent, 2007 CBECS (DOE, 2009) already includes in the survey buildings questionnaire a few questions covering this issue. 
Finally, we stress two points. First, there are limitations in using averages of energy consumption as a proxy for end-use energy intensities: calculated average consumptions, as presented in Figure 1, do not match the statistically developed EUI estimates (which are more accurate than the averages). Second, it would also be important to take into account building envelope and other physical properties, as well as how the facilities are operated. These issues may have significant influence on building end-use energy intensity, and can also be a source of split incentives between landlords and tenants.

\section{Acknowledgments}

This work was supported by the U.S. Department of Energy under Contract No. DE-AC0205CH11231. We acknowledge Amol Pahdke for early suggestions and discussions on statistical procedures, and Jonathan G. Koomey and Alan Meier for their comments on a draft version of this report.

\section{References}

Baardsen, B (2007): "Market Barriers Affecting Water Heating in Norway." In Mind the Gap - Quantifying Principal-Agent Problems in Energy Efficiency. International Energy Agency. Paris, France.

Bjorndalen, J and Bugge, J (2007): "Market Barriers Related to Commercial Office Space Leasing in Norway." In Mind the Gap - Quantifying Principal-Agent Problems in Energy Efficiency. International Energy Agency. Paris, France.

Brown, M A (2001): "Market failures and barriers as a basis for clean energy policies." Energy Policy 29 (14): 1197-1207.

DeCanio, S J (1993): “Barriers within firms to energy efficient investments.” Energy Policy 21 (9): 906-914.

DOE (2006a): 2003 CBECS Public Use Microdata Files. Energy Information Administration, U.S. Department of Energy. http://www.eia.doe.gov/emeu/cbecs/cbecs2003/public_use_2003/cbecs_pudata2003.html.

DOE (2008a): Commercial Buildings Energy Consumption Survey website. Energy Information Administration, U.S. Department of Energy. http://www.eia.doe.gov/emeu/cbecs/.

DOE (2008b): Annual Energy Review 2007. Energy Information Administration, U.S. Department of Energy.

DOE (2008c): Estimation of Energy End-Use Consumption: CBECS 2003. Energy Information Administration, U.S. Department of Energy. http://www.eia.doe.gov/emeu/cbecs/tech_end_use.html.

DOE (2009): 2007 CBECS: Building Questionnaire (Form EIA-871A, Draft 7). Energy Information Administration, U.S. Department of Energy.

Dohrmann, D R et alli (2002): "Remodeling and Renovation of Nonresidential Buildings in California." Nonresidential Remodeling and Renovation (NRRR) Study, Program Measurement and Evaluation. California DSM Measurement Advisory Committee (CALMAC), California Energy Commission, CA, USA.

EPA (2007): ENERGY STAR Performance Ratings-Methodology for Incorporating Source Energy Use. U.S. EPA - U.S. DOE. http://www.energystar.gov/ia/business/evaluate_performance/site_source.pdf. 
Howarth, R B and Andersson, B (1993): "Market barriers to energy efficiency." Energy Economics 15 (4): $262-272$.

Howarth, R B et alli (2000): "The economics of energy efficiency: insights from voluntary participation programs." Energy Policy 28 (6-7): 477-486.

IEA (2007a): Quantifying the Effects of Market Failures in the End-Use of Energy. Report prepared by the American Council for an Energy-Efficient Economy, Washington, DC, to the International Energy Agency, Paris, France.

IEA (2007b): Mind the Gap-Quantifying Principal-Agent Problems in Energy Efficiency. International Energy Agency. Paris, France.

IEA (2008): Energy Technology Perspectives 2008-Scenarios and Strategies to 2050. International Energy Agency. Paris, France.

Jaffe, A B and Stavins, R N (1994a): "Energy-Efficiency Investments and Public Policy." The Energy Journal 15 (2): 43-65.

Jaffe, A B and Stavins, R N (1994b): “The energy-efficiency gap-What does it mean?" Energy Policy 22 (10): 804-810.

Jewell, M T (2002): "Making Energy Efficiency Work in Multi-Tenant Buildings.” In 13th National Energy Services Conference Proceedings, Association of Energy Service Professionals. Jupiter, FL, USA.

Joosen, S et alli (2007): "Space Heating in Rented Houses in The Netherlands." In Mind the GapQuantifying Principal-Agent Problems in Energy Efficiency. International Energy Agency. Paris, France.

Koomey, J G (1990): "Energy Efficiency in New Office Buildings: An Investigation of Market Failures and Corrective Policies." Ph.D. Dissertation, Energy and Resources Group, University of California, Berkeley, CA, USA.

Koomey, J G et alli (2001): "Addressing energy-related challenges for the U.S. buildings sector: Results from the clean energy futures study." Energy Policy 29 (14): 1209-1221.

Levine, M D et alli (1994): Energy Efficiency, Market Failures, and Government Policy. LBNL-35376, ORNL/CON-383, Lawrence Berkeley National Laboratory and Oak Ridge National Laboratory.

Meier, A and Eide, A (2007): How many people actually see the price signal? Quantifying market failures in the end use of energy. LBNL 63384, Lawrence Berkeley National Laboratory. Berkeley, CA, USA.

Murtishaw, S and Sathaye, J A (2006): Quantifying the Effect of the PA Problem on U.S. Residential Energy Use. LBNL 59773, Lawrence Berkeley National Laboratory. Berkeley, CA, USA.

Reed, J H et al. (2004): Who Plays and Who Decides. The Structure and Operation of the Commercial Building Market. Innovologie LLC. Rockville, MD, USA.

Sorrell, S et alli (2000): Reducing Barriers to Energy Efficiency in Public and Private Organizations. Project JOS3CT970022, Environment and Energy Programme, SPRU Science and Technology Policy Research, University of Sussex, Faimer, UK. 
Takahashi, M and Asano, H (2007): "Energy Use Affected by Principal-Agent Problem in Japanese Commercial Office Space Leasing." In Mind the Gap-Quantifying Principal-Agent Problems in Energy Efficiency. International Energy Agency. Paris, France.

Visser, E and Harmelink, M (2007): "The Case of Energy Use in Commercial Offices in the Netherlands." In Mind the Gap-Quantifying Principal-Agent Problems in Energy Efficiency. International Energy Agency. Paris, France. 